\title{
OCB DAN QWL TERHADAP KINERJA KARYAWAN PT. SUMBER NUSANTARA ADITYA PRATAMA
}

\author{
${ }^{*}$ Phonny Aditiawan Mulyana ${ }^{1}$, Mochamad Mockhlas' ${ }^{2}$ Rina Maretasari ${ }^{3}$, Moch. Dwi Prasetyo ${ }^{4}$ \\ 1,2,3,4 Program Studi Manajemen, Fakultas Ekonomi dan Bisnis, Universitas Muhammadiyah Surabaya \\ ${ }^{*}$ phonny.aditiyawan@fe.um-surabaya.ac.id
}

\begin{tabular}{l}
\hline Informasi Artikel \\
\hline Draft awal: September 2021 \\
Revisi : September 2021 \\
Diterima : September 2021 \\
Available online: September 2021
\end{tabular}

Keywords: Organizational Citizenship Behavior (OCB), Quality Of Work Life (QWL) and Employee Performance

Tipe Artikel : Research paper

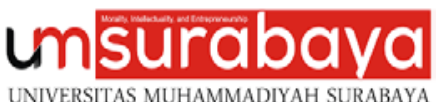

Diterbitkan oleh Universitas Muhammadiyah Surabaya

\begin{abstract}
The purpose of this study was to determine and analyze the influence of Organizational Citizenship Behavior (OCB) and Quality of Work Life $(Q W L)$ on Employee Performance of PT. Sumber Nusantara Aditya Pratama. The location of this research is located at PT. Sumber Nusantara Aditya Pratama is located on Jl. Margomulyo Indah Blok H-11, Surabaya, Jawa Timur with research time from July 2020 to September 2020. Testing of the accuracy of respondent reactions was carried out by distributing questionnaires at PT. Sumber Nusantara Aditya Pratama and is an employee with a total of 70 respondents.
\end{abstract}

The test method uses Multiple Linear Regression Analysis with SPSS for Windows Version 24. The conclusions obtained are: (1) Organizational Citizenship Behavior (OCB) has an effect on Employee Performance at PT. Sumber Nusantara Aditya Pratama Surabaya, (2) Quality of Work Life $(\mathrm{QWL})$ has an effect on Employee Performance at PT. Sumber Nusantara Aditya Pratama Surabaya, (3) Organizational Citizenship Behavior (OCB) and Quality of Work Life (QWL) have a simultaneous effect on Employee Performance at PT. Sumber Nusantara Aditya Pratama Surabaya, (4) From the results of the coefficient of determination, an adjusted $\mathrm{R} 2$ value of $59 \%$ is obtained which can be explained by 59\% of Organizational Citizenship Behavior (OCB) and Quality of Work Life (QWL). While $41 \%$ of employee performance variables at PT. Sumber Nusantara Aditya Pratama Surabaya is explained by other variables

Tujuan penelitian ini adalah untuk mengetahui dan menganalisis Pengaruh Organizational Citizenship Behavior (OCB) Dan Quality Of Work Life (QWL) Terhadap Kinerja Karyawan PT. Sumber Nusantara Aditya Pratama. Lokasi penelitian ini bertempat di PT. Sumber Nusantara Aditya Pratama berlokasi di Jl. Margomulyo Indah Blok H-11, Surabaya, Jawa Timur dengan waktu penelitian Juli 2020 sampai September 2020. Pengujian terhadap ketepatan reaksi responden dilakukan dengan membagikan kuesioner di PT. Sumber Nusantara Aditya Pratama dan merupakan karyawan dengan jumlah 70 responden.

Metode pengujian menggunakan Analisis Regresi Linier Berganda dengan Program SPSS for Windows Versi 24. Kesimpulan yang diperoleh bahwasannya: (1) Organizational Citizenship Behavior (OCB) berpengaruh terhadap Kinerja Karyawan di PT. Sumber Nusantara Aditya Pratama Surabaya, (2) Quality of Work Life (QWL) berpengaruh terhadap Kinerja Karyawan di PT. Sumber Nusantara Aditya Pratama Surabaya, (3) Organizational Citizenship Behavior (OCB) dan Quality of Work Life (QWL) berpengaruh secara simultan terhadap Kinerja Karyawan di PT. Sumber Nusantara Aditya Pratama Surabaya, (4) Dari hasil koefisien determinasi, diperoleh nilai adjusted R2 sebesar 59\% yang dapat dijelaskan sebesar 59\% Organizational Citizenship Behavior (OCB) dan Quality of Work Life (QWL). Sedangkan 41\% variabel Kinerja Karyawan di PT. Sumber Nusantara Aditya Pratama Surabaya dijelaskan oleh variabelvariabel lainnya. 


\section{PENDAHULUAN}

Pertumbuhan perekonomian di Indonesia mengalami perubahan ke arah yang lebih baik. Perkembangan segi perekonomian di Indonesia saat ini dapat dirasakan dari tumbuh berkembangnya proyek-proyek pembangunan sehingga lebih banyak pula para kontraktor yang ada. Kontraktor merupakan perusahaan yang melakukan kontrak kerja dengan orang atau perusahaan lain untuk persewaan alat-alat berat atau menyelesaikan jasa tertentu. Bidang kerjanya seperti pembangunan gedung, pembuatan jalan raya, pengisian lahan dan pemotongan.

Persaingan bisnis dalam bidang kontraktor pertahanan dan sipil pada zaman ini sangatlah ketat, terlebih pada negeri ini. Indonesia dengan luas wilayah 1.913.578,68 kilometer persegi yang didapat dari (bps.go.id), merupakan pasar yang sangat luas dan menjajikan bagi perusahaan untuk dapat meraih keuntungan dan berkembang pesat didalamnya, akan tetapi hal ini tidaklah mudah karena telah banyak perusahaan-perusahaan asing yang ikut meramaikan pasar dibidang kontraktor pertahanan dan sipil di negeri ini.

Menurut (Boone \& Kurtz, 2008, p. 8) hal itu dapat dilakukan jika perusahaan mengacu pada empat input dasar : sumber daya alam, modal, sumber daya manusia, dan kewirausahaan. Karena ke-empat input yang dimiliki perusahaan bersifat terbatas sehingga perusahaan dituntut mampu memperdayakan dengan optimal penggunaannya untuk untuk kelangsungan hidup perusahaannya.

Diantara berbagai sumber daya yang dimiliki perusahaan, Sumber Daya Manusia (SDM) menempati posisi strategis diantara sumber daya lainnya. Tanpa SDM, sumber daya lain yang dimiliki oleh organisasi tidak dapat dimanfaatkan apalagi untuk dikelola menjadi suatu produk. Dalam perkembangannya pastilah menitik beratkan pada sumber daya manusia (human resource) guna menjalankan fungsinya dengan optimal, khususnya dalam menghadapi perubahan lingkungan yang terjadi. Dengan demikian kemampuan teknis, teoritis, konseptual, dan moral dari berbagai pelaku organisasi di semua tingkat pekerjaan amat dibutuhkan.
Sejalan dengan kondisi tersebut, PT. Sumber Nusantara Aditya Pratama sebagai salah satu pelaku usaha dibidang kontraktor pertahanan dan sipil di Kota Surabaya dituntut untuk meningkatkan kemampuan dalam menghadapi persaingan, salah satunya adalah dengan memperhatikan faktor tenaga kerja. Berbagai strategi pun banyak dilakukan oleh perusahaan tersebut untuk dapat mempertahankan dan meningkatkan daya saing terhadap perusahaan lainnya. Mereka sadar bahwa Sumber Daya Manusia (SDM) yang tangguhlah yang dapat membuat sebuah perusahaan mempunyai keunggulan kompetitif.

PT. Sumber Nusantara Aditya Pratama adalah kontraktor pertanahan dan sipil yang menyediakan konstruksi sipil, pengisian lahan, pemotongan dan pengisian, serta layanan penyewaan alat berat dan transportasi. Berdirinya PT. Sumber Nusantara Aditya Pratama dibangun pada tahun 1991, dan telah membuktikan kualitasnya dalam menangani proyek publik dan swasta.

Organisasi pada umumnya percaya bahwa untuk mencapai keunggulan harus mengusahakan kinerja hingga ke individualnya dengan semaksimal mungkin, karena pada dasarnya kinerja individu akan mempengaruhi kinerja tim atau kelompok kerja, dan secara keseluruhan kinerja yang mereka lakukan akan berdampak dengan baik dan buruknya kinerja sebuah organisasi.

(Tambe \& Shanker, 2014, p. 68), berbicara tentang kinerja selalu berkaitan dengan budaya perilaku di dalam organisasi itu sendiri. Perilaku kewarganegaraan dalam organisasi atau Organizational Citizenship Behavior (OCB) merupakan konsep yang baru dalam hal analisis kinerja. Konsep ini menjelaskan bahwa perilaku OCB dilakukan oleh seorang individu dengan penuh kebebasan (sekehendak hati) dalam menentukan sesuatu dan saling pengertian dengan tanpa adanya permintaan imbalan atau ganjaran formal lainnya terhadap organisasi, sehingga perilaku ini sangat membantu dan menguntungkan organisasi. Konsep perilaku ini pertama kali diperkenalkan pada pertengahan tahun 1980-an oleh Dennis Organ dan terus berkembang dan meluas.

Kemudian salah satu cara untuk meningkatkan kualitas kinerja karyawan dibutuhkan faktor pendorong yang harus 
diperhatikan, yaitu kualitas kehidupan kerja. Quality of Work Life (Kualitas kehidupan kerja) merupakan salah satu pendekatan sistem manajemen untuk mengkoordinasikan dan menghubungkan potensi Sumber Daya Manusia, dimana kualitas kehidupan kerja dalam organisasi sebagai suatu upaya pimpinan untuk memenuhi kebutuhan anggota maupun organisasi secara simultan dan berkesinambungan.

Perusahaan dapat menekankan kinerja terbaik yang dihasilkan dengan cara meningkatkan kualitas kehidupan kerja karyawannya. Quality of Work Life (QWL) merupakan program yang mencakup cara untuk meningkatkan kulaitas kehidupan dengan menciptakan karyawan yang lebih baik (Nawawi, 2008, p. 53). Semakin baik kualitas kehidupan kerja karyawan maka semakin baik pula kinerja yang diberikan oleh karyawan, sehingga tujuan dari organisasi semakin cepat tercapai.

Dari standar penilaian kinerja karyawan PT. Sumber Nusantara Aditya Pratama tersebut, didapatkan hasil rekapitulasi kinerja selama 4 (empat) tahun terakhir pada 2017 hingga tahun 2020 sebagai berikut :

Tabel 1. Hasil Penilaian Kinerja Karyawan PT. Sumber Nusantara Aditya Pratama 2017-2020

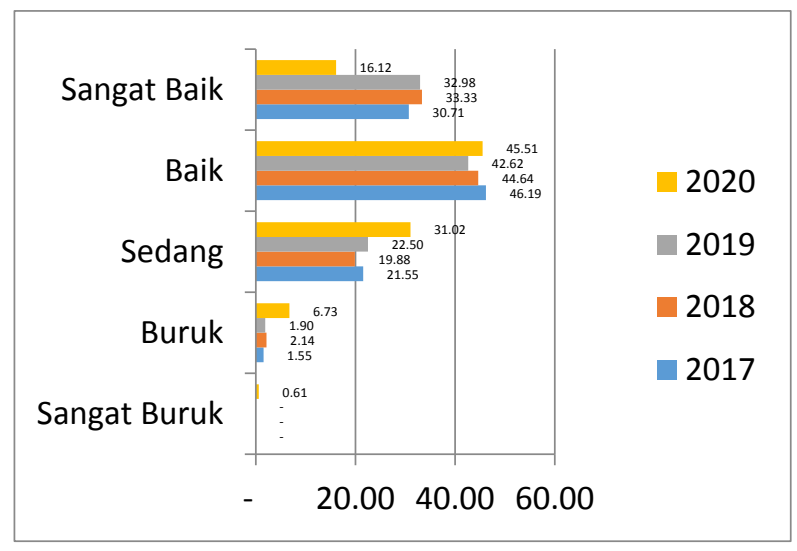

Sumber : PT. Sumber Nusantara Aditya Pratama, 2020

Berdasarkan Tabel 1 dapat dilihat hasil rekapitulasi penilaian kinerja karyawan selama 4 (empat) tahun terakhir pada tahun 2017 hingga tahun 2020. Bahwa kinerja karyawan PT. Sumber Nusantara Aditya Pratama dalam kategori baik yang mendapatkan nilai rata-rata paling tinggi. Namun pada tahun 2020 terjadi lonjakan pada nilai KPI dengan keterangan: pada kategori Sangat Buruk yang awalnya tidak pernah terjadi, sekarang menjadi $0.61 \%$, kemudian penilaian KPI pada kategori Buruk yang dari rata-rata dibawah $1.87 \%$ pada tahun 2020 menjadi 6.73\%, pada kategori penilaian KPI kategori Sedang mengalami kenaikan dari rata-rata $21.31 \%$ menjadi $31.02 \%$, pada kategori penilaian KPI kategori Baik mengalami kenaikan dari rata-rata $44.84 \%$ sekarang menjadi 45.51\%, dan sisanya kategori Sangat Baik mengalami penurunan yang drastis dari rata-rata $32.34 \%$ menjadi $16.12 \%$. Hal ini tidak luput dari adanya dampak Covid-19 yang terjadi di Indonesia yang terjadi pada kisaran dari bulan September 2019 hingga sekarang bulan September 2020.

Terlepas dari dampak Covid-19 banyak pencapaian demi pencapaian pun telah diukir oleh PT. Sumber Nusantara Aditya Pratama dalam negeri ini, tentunya hal tersebut tidaklah lepas dari pengaruh kinerja individu karyawan dalam perusahaan. Maka, untuk mencapai keunggulan tersebut dibutuhkan perhatian khusus dari perusahaan maupun karyawan itu sendiri untuk dapat mencapai segala tujuan yang telah dibuat.

Berbagai strategi pun banyak dilakukan oleh perusahaan tersebut untuk dapat mempertahankan dan meningkatkan daya saing terhadap perusahaan lainnya. Mereka sadar bahwa Sumber Daya Manusia (SDM) yang tanggulah yang dapat membuat sebuah perusahaan mempunyai keunggulan kompetitif.

Mereka percaya bahwa keberhasilan perusahaan sangat dipengaruhi oleh kinerja individu karyawan. Sampai saat ini kinerja masih merupakan permasalahan yang dihadapi oleh pihak manajemen, sehingga manajemen perlu mengetahui hal-hal apa saja yang dapat mempengaruhi kinerja karyawan.

Perilaku yang menjadi tuntutan pada organisasi saat ini tidak hanya perilaku in-role, tetapi juga perilaku extra-role atau perilaku yang melebihi tuntutan peran di tempat kerja, dimana perilaku extra-role yang dimaksud adalah dengan tumbuhnya Organizational Citizenship Behavior (OCB) dalam sebuah organisasi. Perilaku ini cenderung melihat seorang (karyawan) sebagai makhluk sosial, dibanding sebagai makhluk individu yang hanya mementingkan diri sendiri. 
Di dalam kegiatan perusahaan aplikasi prinsip-prinsip OCB telah diwujudkan PT. Sumber Nusantara Aditya Pratama dalam berbagai bentuk. Salah satunya adalah ketika perusahaan mengadakan perayaan HUT (Hari Ulang Tahun) PT. Sumber Nusantara Aditya Pratama para karyawan ikut serta dapat terlibat dan turut menyukseskan berbagai acara untuk memeriahkan bahkan hingga melewati batas jam kerja mereka untuk menghias kantor mereka dalam rangka HUT kantornya.

Hal tersebut tidak akan mudah terjadi bila perusahaan kurang memperhatikan Quality of Work Life (QWL) bagi karyawan nya lebih dari itu perusahaan akan menghadapi kondisi dimana karyawan lebih memilih untuk pindah ke perusahaan lain, karena mereka lebih memilih untuk bekerja di perusahaan lain yang menerapkan berbagai faktor kualitas kehidupan kerja yang lebih menjanjikan.

Membina dan menjaga semangat karyawan perlu dilakukan secara berkelanjutan agar karyawan terbiasa dan mempunyai semangat kerja yang tinggi karena hal ini akan berdampak terhadap produktifitas kerja karyawan tersebut. Salah satu bentuk perwujudan QWL pada PT.Sumber Nusantara Aditya Pratama adalah memberikan minimal gaji yang sesuai dengan Upah Minimum Regional (UMR) dan hal tersebut belum ditambah dengan insentif. Gaji yang diberikan pun disesuaikan dengan tingkat jabatan karyawan di perusahaan tersebut.

Berdasarkan penjelasan di atas bertujuan untuk menganalisis pengaruh tentang Organizational Citizenship Behavior (OCB) yang dikaitkan dengan Quality of Work Life (QWL) terhadap kinerja karyawan di di PT. Sumber Nusantara Aditya Pratama.

\section{METODE PENELITIAN}

\section{Ruang Lingkup Penelitian}

Penelitian ini mencakup dalam ruang lingkup sumber daya manusia yang membahas mengenai pengaruh Organizational Citizenship Behavior (OCB) dan Quality of Work Life (QWL) terhadap kinerja karyawan. Berdasarkan hal ini maka dibutuhkan perusahaan yang telah terbukti dengan berbagai keunggulannya guna membuktikan bahwa OCB dan QWL mempengaruhi kinerja karyawan, yang secara keseluruhan ikut mempengaruhi kinerja perusahaan. Oleh karena itu peneliti memilih PT. Sumber Nusantara Aditya Pratama sebagai objek penelitian. Hal ini dikarenakan fenomena dan kapasitas karyawan yang mendukung sebagai salah satu syarat penelitian.

\section{Identifikasi Variabel}

Pengertian variabel penelitian menurut (Sugiyono, 2010, p. 2) adalah segala sesuatu yang berbentuk apa saja yang ditetapkan oleh peneliti untuk dipelajari sehingga diperoleh informasi tentang hal tersebut, kemudian ditarik kesimpulannya. Menurut Hatch dan Fardahany dalam (Sugiyono, 2010, p. 3), secara teoritis variabel sendiri dapat didefinisikan sebagai atribut, seseorang, atau objek yang mempunyai "variasi" satu orang dengan yang lainnya atau satu objek dengan objek yang lain. Penelitian ini menggunakan dua variabel yaitu:

\section{a. Variabel Bebas (Independent variable)}

$$
\text { Variabel independen yang }
$$

dilambangkan dengan (X) adalah variabel stimulus, prediktor, antecedent. Dalam bahasa indonesia sering disebut variabel bebas. Variabel yang menjadi sebab perubahannya atau timbulnya variabel dependen (terikat). Variabel independen dalam penelitian ini adalah:

\section{Organizational Citizenship Behavior (X1)}

2. Quality of Work Life (X2)

b. Variabel Terikat (dependent variable)

Variabel ini sering disebut sebagai variable output, kriteria, konsekuen. Dalam bahasa Indonesia sering disebut variable terikat. Variabel terikat merupakan variable yang dipengaruhi atau yang menjadi akibat, karena adanya variable bebas (Sugiyono, 2010, p. 4). Dalam penelitian ini yang menjadi variable dependen adalah: Kinerja Karyawan (Y).

\section{Teknik Pengumpulan Data}

1. Penelitian kepustakaan

Yaitu penelitian yang diperoleh dengan cara membaca dan mempelajari literatur-literatur, dokumentasi yang terkait dengan objek dan sasaran yang diteliti.

2. Penelitian lapangan

Kuesioner, yaitu teknik pengumpulan informasi yang memungkinkan analisis mempelajari sikapsikap, keyakinan, perilaku, dan karakteristik beberapa orang utama di dalam organisasi 
yang bisa terpengaruh oleh sistem yang sudah ada (Siregar, 2013, p. 132).

Jenis skala pengukuran yang digunakan adalah skala interval. Menurut (Riduwan \& Akdon, 2013, p. 14) skala interval adalah skala yang menunjukan jarak antara satu data dengan data yang lain dan mempunyai bobot yang sama. Kemudian setiap indikator pertanyaan dari kuesioner diukur dengan skala Likert, yakni skala yang digunakan untuk mengukur sikap, pendapat dan persepsi seseorang atau kelompok tentang kejadian sosial atau gejala sosial (Riduwan \& Akdon, 2013, p. 16). Dalam kuesioner yang digunakan peneliti, setiap pertanyaan terdiri dari 5 (lima) kategori jawaban, yaitu:

1. Sangat setuju/Sangat baik Skor $=5$

2. Setuju/Baik Skor $=4$

3. Cukup setuju/Cukup baik Skor $=3$

4. Tidak Setuju/Tidak baik Skor $=2$

5. Sangat tidak setuju/Sangat tidak baik Skor $=1$

\section{Populasi dan Sampel}

Menurut (Sugiyono, 2010, p. 61) populasi adalah wilayah generalisasi yang terdiri atas: obyek/subyek yang mempunyai kualitas dan karakteristik tertentu yang ditetapkan oleh peneliti untuk dipelajari dan kemudian ditarik kesimpulannya. Dalam penelitian ini yang menjadi populasi adalah karyawan pada PT. Sumber Nusantara Aditya Pratama sejumlah 70 orang. Dalam penelitian ini sampel yang akan diteliti adalah keseluruhan dari populasi yang ada yaitu 70 karyawan, maka peneliti memakai sampel jenuh atau diambil keseluruhan populasi untuk dijadikan sampel tanpa harus menggambil sampel dalam jumlah tertentu (Ticoalu, 2013, p. 784). Sampel diambil berdasarkan teknik sampling berdasarkan nonprobabilitas (nonprobability sampling), dengan teknik purposive sampling yakni teknik yang digunakan dalam pengambilan sampel secara sengaja sesuai dengan persyaratan yang ditentukan, yakni karyawan yang memiliki masa kerja minimal tiga bulan dan minimal lulusan Sekolah Menengah Pertama (SMP), dengan pertimbangan dalam jangka waktu tiga bulan dan minimal lulusan SMP karyawan telah memiliki pengalaman, pengetahuan, dan keterampilan kerja yang cukup, sehingga dapat dievaluasi perilaku OCB serta telah cukup merasakan QWL dalam perusahaan tersebut.

\section{Sumber Data}

\section{a. Data Primer}

Yaitu data yang biasanya didapat dari subjek penelitian dengan cara melakukan pengamatan atau percobaan. Cara untuk mendapatkan data primer biasanya melalui pengamatan langsung, subjek diberi lembar yang berisi pertanyaan untuk diisi, pertanyaan yang ditujukan untuk responden (Sujarweni \& Endrayanto, 2012, p. 21).

b. Data Sekunder

Data Sekunder adalah data yang tidak langsung diperoleh dari sumber pertama dan telah tersusun dalam bentuk dokumen tertulis. Data ini biasanya diperoleh dari buku-buku cetak (Sujarweni \& Endrayanto, 2012, p. 21).

\section{HASIL DAN PEMBAHASAN}

\section{Hasil}

\section{Gambaran Umum Objek Penelitian}

PT. Sumber Nusantara Aditya Pratama adalah kontraktor tanah dan sipil yang menyediakan jasa konstruksi sipil, penimbunan tanah, potong dan penimbunan, serta jasa sewa alat berat dan transportasi. Sejak didirikan pada tahun 1991, PT. Sumber Nusantara Aditya Pratama telah membuktikan kualitasnya dalam menangani proyek publik dan swasta. Berdasarkan pengalaman kerja yang kuat, sumber daya manusia yang andal, dan penerapan teknologi informasi yang efisien, kami percaya bahwa kami dapat bekerja sama dengan perusahaan publik maupun swasta, pengembang, pemilik tanah, gudang dan pabrik dalam mewujudkan proyek impian mereka dengan kualitas kerja yang andal, waktu dan biaya.

Seiring dengan globalisasi, PT. Sumber Nusantara Aditya Pratama selalu mengutamakan sistem, metode, dan teknologi informasi dalam setiap proyek yang kami tangani, mulai dari penimbunan lahan hingga pembangunan infrastruktur. Selain itu, kami juga mengutamakan keselamatan, efisiensi dan nilai ekonomis dalam menangani semua jenis proyek agar dapat memberikan kualitas kerja yang prima.

Terakhir tapi bukan yang akhir, dapat disimpulkan bahwa berdasarkan pengetahuan dan pengalaman, PT. Sumber Nusantara Aditya Pratama sebagai kontraktor tanah dan sipil siap untuk mewujudkan setiap proyek dengan 
kualitas yang sangat baik dan memuaskan. PT. Sumber Nusantara Aditya Pratama berharap dapat bekerja dan menghadapi masa depan yang lebih cerah bersama.

\section{Gambaran Penyebaran Kuesioner}

Penelitian ini menggunakan kuesioner yang disebarkan langsung kepada responden PT. Sumber Nusantara Aditya Pratama Surabaya. Responden dalam penelitian ini adalah karyawan PT. Sumber Nusantara Aditya Pratama Surabaya sejumlah 70 orang kuesioner yang dikirimkan kepada seluruh responden dapat dibuat ikhtisarnya sebagai berikut:

\section{Gambaran Umum Kuesioner}

Berdasarkan Tabel 2 dapat dilihat bahwa deskripsi data yang akan disajikan dari hasil penelitian ini adalah untuk memberikan gambaran secara umum mengenai kuesioner yang akan disebar untuk responden. Jumlah pertanyaan pada kuesioner yang dikirimkan sebanyak 70 0rang pertanyaan yang ikhtisarnya sebagai berikut:

Tabel 2 Gambaran Umum Kuesioner

\begin{tabular}{|c|l|c|c|}
\hline Var & \multicolumn{1}{|c|}{ Variabel } & $\begin{array}{l}\text { Skala } \\
\text { Likert }\end{array}$ & Jumlah \\
\hline $\mathrm{X} 1$ & $\begin{array}{l}\text { Variabel } \\
\text { Organizational } \\
\text { Citizenship } \\
\text { Behavior (OCB) }\end{array}$ & $1-5$ & 10 Pertanyaan \\
$\mathrm{X} 2$ & $\begin{array}{l}\text { Variabel Quality of } \\
\text { Work Life (QWL) }\end{array}$ & $1-5$ & 11 Pertanyaan \\
\hline $\mathrm{Y}$ & Kinerja Karyawan & $1-5$ & 7 Pertanyaan \\
\hline \multicolumn{3}{|l|}{ Jumlah Pertanyaan } & 28 Pertanyaan \\
\hline
\end{tabular}

Sumber data: Hasil Olahan Kuesioner, 2020

\section{Karakteristik Responden}

Responden dalam penelitian ini merupakan karyawan PT. Sumber Nusantara Aditya Pratama Surabaya sebanyak 70 orang. Keseluruhan responden tersebut dapat diketahui karakteristiknya berdasarkan jenis kelamin, usia, pendidikan, pekerjaan, dan pengeluaran per bulan.

\section{Uji Serentak (Uji F)}

Uji F dilakukan untuk mengetahui apakah variabel Organizational Citizenship Behavior (OCB) $\left(\mathrm{X}_{1}\right)$ dan Quality of Work Life (QWL) $\left(\mathrm{X}_{2}\right)$ secara simultan (bersama-sama) berpengaruh terhadap variable Kinerja Karyawan PT. Sumber Nusantara Aditya
Pratama Surabaya. Hasil uji simultan dapat disajikan pada Tabel 3 sebagai berikut:

Tabel 3. Hasil Uji F

ANOVA $^{\mathrm{a}}$

\begin{tabular}{lccccc}
\hline \multicolumn{1}{c}{ Model } & $\begin{array}{c}\text { Sum of } \\
\text { Squares }\end{array}$ & df & $\begin{array}{c}\text { Mean } \\
\text { Square }\end{array}$ & F & Sig. \\
\hline Regression & 445.028 & 2 & 222.514 & 50.638 & $.000^{\mathrm{b}}$ \\
Residual & 294.414 & 67 & 4.394 & & \\
Total & 739.443 & 69 & & & \\
\hline
\end{tabular}

a. Dependent Variable: Tot_Y

b. Predictors: (Constant), Tot_X2, Tot_X1

Sumber : Hasil Output SPSS 24

Berdasarkan Tabel 3 diatas dapat diketahui bahwa nilai signifikansi yang diperoleh sebesar $0,000 \quad(\mathrm{p}<0,05)$. Dengan demikian dapat disimpulkan bahwa variabel Organizational Citizenship Behavior (OCB) $\left(\mathrm{X}_{1}\right)$ dan Quality of Work Life (QWL) $\left(\mathrm{X}_{2}\right)$ secara simultan (bersama-sama) berpengaruh terhadap variable Kinerja Karyawan PT. Sumber Nusantara Aditya Pratama Surabaya. Dengan kata lain disimpulkan bahwa secara simultan variabel independen mempunyai pengaruh yang signifikan terhadap variabel dependen.

\section{Uji Parsial (Uji t)}

Uji t digunakan untuk menguji koefisien regresi secara parsial dari variabel independennya, apakah masing-masing variabel Organizational Citizenship Behavior (OCB) $\left(\mathrm{X}_{1}\right)$ dan Quality of Work Life (QWL) $\left(\mathrm{X}_{2}\right)$ berpengaruh terhadap variabel Kinerja Karyawan PT. Sumber Nusantara Aditya Pratama Surabaya. Kriteria Kinerja Karyawan yaitu dengan melihat nilai signifikansi masingmasing variabel yang akan dibandingkan nilai derajat kesalahan sebesar 5\%.

Tabel 4 Hasil Uji t

Coefficients $^{\mathrm{a}}$

\begin{tabular}{cccccc}
\multirow{2}{*}{ Model } & \multicolumn{2}{c}{ Unstand. Coeff } & \multirow{2}{*}{$\mathrm{t}$} & Sig. \\
\cline { 3 - 4 } & & $\mathrm{B}$ & Std. Error & & \\
\hline \multirow{2}{*}{1} & (Constant) & 2.770 & 3.090 & .897 & 373 \\
& Tot_X1 & 482 & 093 & 5.207 & 000 \\
& Tot_X2 & 146 & 045 & 3.246 & 002 \\
\hline
\end{tabular}

a. Dependent Variable: Tot_Y

Sumber : Hasil Output SPSS 24 (Lampiran 6)

Berdasarkan Tabel 4 diatas, dapat dituliskan model regresi linier berganda mengenai pengaruh variabel Organizational Citizenship Behavior (OCB) $\left(\mathrm{X}_{1}\right)$ dan Quality of Work Life (QWL) $\left(\mathrm{X}_{2}\right)$ terhadap variabel Kinerja 
Karyawan di PT. Sumber Nusantara Aditya Pratama Surabaya sebagai berikut:

$$
y=2.770+0,482 X_{1}+0,146 X_{2}+\varepsilon
$$
berikut:

Interpretasi hasil uji parsial adalah sebagai

1. Konstanta $(\alpha)$ sebesar 2.770 memberi arti apabila variabel bebas Organizational Citizenship Behavior (OCB) $\left(\mathrm{X}_{1}\right)$ dan Quality of Work Life (QWL) (X $\left.\mathrm{X}_{2}\right)$ adalah bernilai Konstan, maka besarnya variabel terikat yaitu Kinerja Karyawan (Y) adalah bernilai sebesar 2.770 satuan.

2. Variabel Organizational Citizenship Behavior (OCB) $\left(\mathrm{X}_{1}\right)$ memiliki koefisien sebesar 0,482 yang menunjukkan pengaruh positif (searah) terhadap Kinerja Karyawan (Y). Apabila Organizational Citizenship Behavior (OCB) $\left(\mathrm{X}_{1}\right)$ bertambah satu satuan, maka Kinerja Karyawan (Y) akan bertambah sebesar 0.482 satuan.

3. Variabel Quality of Work Life (QWL) $\left(\mathrm{X}_{2}\right)$ memiliki koefisien sebesar 0,146 yang menunjukkan pengaruh positif (searah) terhadap Kinerja Karyawan (Y). Apabila Quality of Work Life (QWL) ( $\left.\mathrm{X}_{2}\right)$ bertambah satu satuan, maka Kinerja Karyawan (Y) akan bertambah sebesar 0,146 satuan.

\section{Koefisien Determinasi}

Uji $\mathrm{R}^{2}$ digunakan untuk mengukur seberapa jauh kemampuan model dalam menjelaskan variabel dependen. Dalam penelitian ini koefisien determinasi menggunakan nilai adjusted $\mathrm{R}^{2}$.

Tabel 5 Koefisien Determinasi

\begin{tabular}{ccccc} 
& \multicolumn{3}{c}{ Model Summary } \\
\hline Model & R & R Square & $\begin{array}{c}\text { Adjusted R } \\
\text { Square }\end{array}$ & $\begin{array}{c}\text { Std. Error of } \\
\text { the Estimate }\end{array}$ \\
\hline 1 & $776^{\mathrm{a}}$ & 602 & 590 & 2.096
\end{tabular}

a. Predictors: (Constant), Tot_X2, Tot_X1

b. Dependent Variable: Tot_Y

Sumber : Hasil Output SPSS 24

Dari hasil koefisien determinasi, diperoleh nilai adjusted $\mathrm{R}^{2}$ sebesar 0,590 atau $59 \%$. Hal ini menunjukkan bahwa Kinerja Karyawan di PT. Sumber Nusantara Aditya Pratama Surabaya dapat dijelaskan sebesar 59\% oleh variabel independen yaitu Organizational Citizenship Behavior (OCB) $\left(\mathrm{X}_{1}\right)$ dan Quality of Work Life (QWL) $\left(\mathrm{X}_{2}\right)$. Sedangkan 41\% variabel Kinerja
Karyawan di PT. Sumber Nusantara Aditya Pratama Surabaya dijelaskan oleh variabelvariabel lain diluar variabel independen penelitian ini.

\section{Hasil Hipotesis Penelitian}

Dari hasil penelitian yang dilakukan oleh peneliti diperoleh hasil temuan penelitian yang dapat dijelaskan pada Tabel 6 sebagai berikut:

Tabel 6 Temuan Penelitian

\begin{tabular}{|c|c|}
\hline Hipotesis & Temuan Penelitian \\
\hline H1 & $\begin{array}{l}\text { Terdapat pengaruh yang signifikan } \\
\text { antara Organizational Citizenship } \\
\text { Behavior (OCB) terhadap kinerja } \\
\text { karyawan dengan nilai signifikansi yang } \\
\text { diperoleh sebesar } 0,000(\mathrm{p}<0,05) \text {. }\end{array}$ \\
\hline $\mathrm{H} 2$ & $\begin{array}{l}\text { Terdapat pengaruh yang signifikan } \\
\text { antara Quality of Work Life (QWL) } \\
\text { terhadap kinerja karyawan dengan nilai } \\
\text { signifikansi yang diperoleh sebesar } \\
0,002(\mathrm{p}<0,05) .\end{array}$ \\
\hline H3 & $\begin{array}{l}\text { Terdapat pengaruh yang signifikan } \\
\text { antara Organizational Citizenship } \\
\text { Behavior (OCB) dan Quality of Work } \\
\text { Life (QWL) terhadap kinerja karyawan } \\
\text { dengan nilai signifikansi yang diperoleh } \\
\text { sebesar } 0,000(\mathrm{p}<0,05) \text {. }\end{array}$ \\
\hline
\end{tabular}

Sumber : Hasil Peneliti 2020

\section{Pembahasan}

Pengaruh Organizational Citizenship
Behavior terhadap Kinerja Karyawan
Hipotesis pertama dalam penelitian ini adalah untuk mengetahui pengaruh Organizational Citizenship Behavior (OCB) $\left(\mathrm{X}_{1}\right)$ terhadap Kinerja Karyawan di PT. Sumber Nusantara Aditya Pratama Surabaya. Hasil analisis dengan regresi linier berganda menunjukkan nilai signifikansi sebesar 0,000 $(\mathrm{p}<0,05)$ yang berarti bahwa Organizational Citizenship Behavior $\left(\mathrm{X}_{1}\right)$ berpengaruh secara positif terhadap Kinerja Karyawan di PT. Sumber Nusantara Aditya Pratama Surabaya (Y). Hasil signifikan ini juga salah satunya dipengaruhi oleh faktor pendidikan dimana dari hasil keseluruhan responden dalam penelitian ini didominasi oleh responden yang memiliki pendidikan akhir SMA/SMK yaitu sebanyak 34 responden (48.6\%). Dimana hasil ini mendukung penelitian (Pavalache-Ilie, 2014) yang menyatakan karyawan dengan tingkat pendidikan menengah cenderung lebih terlibat dalam OCB dibandingkan dengan karyawan yang memiliki tingkat pendidikan tinggi. 
Adanya pengaruh yang nyata antara Organizational Citizenship Behavior (OCB) terhadap kinerja karyawan menunjukan Organizational Citizenship Behavior (OCB) merupakan salah satu peran manajemen dalam menciptakan kinerja yang baik dengan memberikan

kesempatan untuk karyawan berpartisipasi dalam organisasi, jaminan keamanan kerja karyawan, memberikan kesempatan untuk mengembangkan karir, penempatan sesuai keahlian, dan melakukan aktivitas yang sesuai aktivitas pokok. Saran pada PT. Sumber Nusantara Aditya Pratama Surabaya supaya tetap mempertahankan kualitas Organizational Citizenship Behavior (OCB) agar supaya Kinerja Karyawan tetap bertahan baik kedepannya, dimungkinkan lebih baik lagi dengan cara memberikan apresiasi kepada karyawan yang memiliki contoh yang baik.

Hasil penelitian ini mendukung teori Jacqueline dalam Bukhari (2008), OCB adalah suatu perilaku extra role, yakni suatu perilaku yang tidak dibutuhkan (disyaratkan) dalam organisasi dan lebih mengandalkan praktek semata terhadap kesedian seorang karyawan sebagai konsekuensinya dalam lingkungan organisasi.

Hasil penelitian ini mendukung penelitian (Hermawati, Suhermin, \& Suci, Jurnal Manajemen, 2019), (Rahma \& Widiartanto, 2016), (Sumiati, Ardiana, \& Pratiwi, 2018) dan (Suparjati \& Priyono, 2018) yang menyatakan bahwa Organizational Citizenship Behavior (OCB) berpengaruh positif dan signifikan terhadap kinerja karyawan melalui perilaku karyawan. Saran kepada

\section{Pengaruh Quality of Work Life terhadap Kinerja Karyawan}

Hipotesis kedua dalam penelitian ini adalah untuk mengetahui pengaruh Quality of Work Life $\left(\mathrm{X}_{2}\right)$ terhadap Kinerja Karyawan di PT. Sumber Nusantara Aditya Pratama Surabaya. Hasil analisis dengan regresi linier berganda menunjukkan nilai signifikansi sebesar $0,002(\mathrm{p}<0,05)$ yang berarti bahwa Quality of Work Life $\left(\mathrm{X}_{2}\right)$ berpengaruh secara positif terhadap Kinerja Karyawan di PT. Sumber Nusantara Aditya Pratama Surabaya (Y). Dapat disimpulkan bahwa hipotesis 2 yang menyatakan bahwa Quality of work life berpengaruh signifikan terhadap kinerja karyawan juga dapat dipengaruhi oleh karakter responden yang sebagian besar sudah bekerja dengan lama bekerja diatas rata-rata yaitu kisaran 3 sampai dengan 5 tahun dengan jumlah karyawan sebanyak 35 karyawan atau setara dengan 50\% jumlah total karyawan, kemudian lama bekerja karyawan terbanyak kedua lebih dari 8 tahun sejumlah 22 karyawan atau setara dengan $31.4 \%$. Hal ini mendukung penelitian (Wenda, 2015) yang mengindikasikan bahwa karyawan yang bekerja lebih lama dengan perusahaan lebih memiliki komitmen. Karyawan yang memiliki komitmen terhadap organisasi akan memiliki keinginan yang kuat dalam bekerja dan mewujudkan tujuan perusahaan karena merasakan quality of work life yang lebih baik.

Adanya pengaruh yang nyata antara Quality of Work Life (QWL) terhadap kinerja karyawan menunjukan Quality

Work Life (QWL) merupakan salah satu peran tiap individu dalam menciptakan kinerja yang baik dengan berkembang dan berpartisipasi dalam mengembangkan karir, karyawan merasa aman dalam bekerja, secara relatif merasa puas serta mendapatkan kesempatan untuk tumbuh dan berkembang. Saran pada PT. Sumber Nusantara Aditya Pratama Surabaya supaya tetap mempertahankan kualitas Quality of Work Life (QWL) agar supaya Kinerja Karyawan tetap bertahan baik kedepannya.

Hasil penelitian ini mendukung teori Quality of Work Life (QWL) sebagai persepsipersepsi karyawan seperti bahwa karyawan merasa aman dalam bekerja, secara relatif merasa puas serta mendapatkan kesempatan untuk tumbuh dan berkembang sebagai layaknya manusia (Cascio, 2006: 24). Hasil dalam penelitian ini sejalan dengan hasil penelitian yang dilakukan oleh (Hastati, Remmang, \& Cahyono, 2020), (Rahma \& Widiartanto, 2016), (Hermawati \& Mas, National Conference On Economic Education , 2016), (Hermawati, Suhermin, \& Suci, Jurnal Manajemen, 2019), dan (Sumiati, Ardiana, \& Pratiwi, 2018) yang menyatakan bahwa Quality of Work Life berpengaruh positif dan signifikan terhadap kinerja karyawan melalui perilaku karyawan.

\section{Pengaruh Organizational Citizenship Behavior (OCB) dan Quality of Work Life (QWL) terhadap Kinerja Karyawan}

Hipotesis ketiga menguji pengaruh Organizational Citizenship Behavior (OCB) dan Quality of Work Life (QWL) terhadap variabel Kinerja Karyawan secara simultan. Hipotesis 
tersebut diuji melalui uji $\mathrm{F}$ yang menunjukkan nilai signifikansi sebesar $0,000 \quad(\mathrm{p}<0,05)$. Sehingga dapat disimpulkan bahwa Organizational Citizenship Behavior (OCB) dan Quality of Work Life (QWL) secara bersamasama berpengaruh terhadap Kinerja Karyawan. Dapat disimpulkan bahwa hipotesis 3 yang menyatakan bahwa Organizational Citizenship Behavior (OCB) dan Quality of Work Life (QWL) secara bersama-sama berpengaruh signifikan terhadap kinerja karyawan dapat diterima. Organizational Citizenship Behavior (OCB) dan Quality of Work Life (QWL) berkontribusi terhadap kinerja karyawan. Hal ini berarti bahwa Organizational Citizenship Behavior (OCB) dan Quality of Work Life (QWL) yang baik mampu meningkatkan kinerja karyawan. Selain dari dua factor tersebut, ada factor lainnya yang mendukung hasil ini yaitu factor demografi responden dari perspektif masa kerja. Dimana pada kategori lama bekerja $>8$ tahun (31.4\%) yang mendukung penelitian (Robbins \& Judge, 2013) yang menyatakan bahwa masa kerja dinyatakan sebagai lamanya kerja seorang karyawan dimana masa kerja ini akan berdampak positif terhadap kinerja karyawan dan kepuasan kerja (Robbins \& Judge, 2013).

Selain dipengaruhi oleh faktor lama bekerja, kinerja perusahaan PT. Sumber Nusantara Aditya Pratama Surabaya juga dipengaruhi oleh factor pendidikan. Pendidikan merupakan faktor penting dalam menentukan kemampuan kerja karyawan. Pendidikan merupakan indikator yang mencerminkan kemampuan seseorang untuk dapat menyelesaikan suatu pekerjaan (Hasibuan, 2011). Dimana dari keseluruhan responden dalam penelitian ini didominasi oleh responden yang memiliki pendidikan akhir SMA/SMK yaitu sebanyak 34 responden (48.6\%). Hal ini sudah sewajarnya mengingat system kerja lebih banyak membutuhkan tenaga. Kembali lagi karena PT. Sumber Nusantara Aditya Pratama Surabaya bergerak pada bidang usaha kontraktor tanah dan sipil yang menyediakan jasa konstruksi sipil, penimbunan tanah, potong dan penimbunan, serta jasa sewa alat berat dan transportasi yang membutuhkan tenaga kerja lebih besar daripada bidang professional.

Kondisi tersebut menunjukkan bahwa proses peningkatkan kinerja sebaiknya dilakukan dengan peningkatkan Organizational Citizenship Behavior bersamaan dengan meningkatkan Quality of Work Life dan akhirnya berdampak pada peningkatan Kinerja. Sarannya guna meningkatkan kinerja karyawan PT. Sumber Nusantara Aditya Pratama Surabaya maka perlu menurunkan tingkat kemungkinan karyawan untuk keluar atau pindah dari perusahaan. Misalnya dengan lebih memperhatikan kesejahteraan karyawan melalui pemberian bonus atau peningkatan gaji karyawan sehingga karyawan merasa lebih dihargai bekerja di peruahaan tersebut.

Nilai koefisien determinasi yang diperoleh sebesar 51\% yang menunjukkan bahwa Kinerja Karyawan di PT. Sumber Nusantara Aditya Pratama Surabaya dapat dijelaskan sebesar 51\% oleh variabel independen yaitu Organizational Citizenship Behavior (OCB) dan Quality of Work Life (QWL).

Hasil penelitian ini sesuai dengan penelitian yang dilakukan oleh (Hermawati \& Mas, National Conference On Economic Education , 2016) dan (Hermawati, Suhermin, \& Suci, Jurnal Manajemen, 2019) yang menunjukkan bahwa secara simultan variabel Organizational Citizenship Behavior (OCB) dan Quality of Work Life (QWL) berpengaruh signifikan terhadap Kinerja Karyawan.

\section{SIMPULAN}

simpulan yang diperoleh berdasarkan penelitian ini adalah sebagai berikut:

1. Organizational Citizenship Behavior (OCB) berpengaruh terhadap Kinerja Karyawan di PT. Sumber Nusantara Aditya Pratama Surabaya yang dapat dibuktikan dengan hasil analisis dengan regresi linier berganda menunjukkan nilai signifikansi sebesar 0,000 $(\mathrm{p}<0,05)$.

2. Quality of Work Life (QWL) berpengaruh terhadap Kinerja Karyawan di PT. Sumber Nusantara Aditya Pratama Surabaya yang dapat dibuktikan dengan hasil analisis dengan regresi linier berganda menunjukkan nilai signifikansi sebesar $0,002(\mathrm{p}<0,05)$.

3. Organizational Citizenship Behavior (OCB) dan Quality of Work Life (QWL) berpengaruh secara simultan terhadap Kinerja Karyawan di PT. Sumber 
Nusantara Aditya Pratama Surabaya yang dapat dibuktikan dengan hasil analisis dengan regresi linier berganda menunjukkan nilai signifikansi sebesar $0,000(\mathrm{p}<0,05)$.

\section{DAFTAR PUSTAKA}

Boone, L. E., \& Kurtz, D. L. (2008). Pengantar Bisnis Kontemporer Edisi Kesebelas. Jakarta : Salemba Empat.

Hasibuan, M. S. (2011). Manajemen Sumber Daya Manusia. Jakarta: PT Bumi Askara.

Hastati, Remmang, H., \& Cahyono. (2020). Indonesian Journal of Business and Management. Pengaruh Kepemimpinan, Kepuasan Kerja, Quality Of Work Life Terhadap Kinerja Karyawan Melalui Perilaku Di Hotel Dinasti Kota Makassar, Halaman: 35-40 .

Hermawati, A., \& Mas, N. (2016, Agustus ). National Conference On Economic Education . Strategi Bersaing: Melalui Capaian Kinerja Human Resources Berbasis Transglobal Leadership Dengan Optimalisasi Organizational Citizenship Behavior Dan Quality Of Work Life (Studi Koperasi Berprestasi Di Jawa Timur).

Hermawati, A., Suhermin, \& Suci, R. P. (2019). Jurnal Manajemen. Efek Implementasi Quality Of Work Life Terhadap Kinerja Sumber Daya Manusia Terintegrasi (Studi Kasus Usaha Mikro Kecil dan Menengah Di Kota Malang), Vol. 5, No. 2, Halaman : 28-33.

Nawawi, H. (2008). Manajemen Sumber Daya Manusia untuk Bisnis yang Kompetitif (Vol. Cetakan Keempat). Yogyakarta: Universitas Gajah Mada Press.

Pavalache-Ilie, M. (2014). Organizational Citizenship Behaviour, Work Satisfaction and Employees' Personality. Procedia - Social and Behavioral Sciences, 489-493.

Rahma, I., \& Widiartanto. (2016). Prosiding Seminar Nasional ASBIS 2016 Politeknik Negeri Banjarmasin. engaruh Quality Of Work Life Dan Komitmen Organisasional Terhadap Kinerja Karyawan Dengan Organizational Citizenship Behavior Sebagai Variabel Intervening Pada Hotel Amanda Hills
Bandungan(ISSN Cetak : 2541-6014 ISSN Online : 2541-6022 ), 166-176.

Riduwan, D. M., \& Akdon, P. D. (2013). Rumus dan Data dalam Analisis Statistika. Bandung: Alfabeta.

Robbins, S. P., \& Judge, T. A. (2013). Organizational Behavior. Pearson Education Limited, Vol. 40.

Siregar, S. I. (2013). Statistik Parametrik untuk Penelitian Kuantitatif. Jakarta: Bumi Aksara.

Sugiyono. (2010). Metode Penelitian Pendidikan Pendekatan Kuantitatif, kualitatif dan R\&D. Bandung: Alfabeta.

Sujarweni, W. W., \& Endrayanto, P. (2012). Statistika Untuk Penelitian. Yogyakarta: Graha Ilmu.

Sumiati, Ardiana, I. D., \& Pratiwi, A. I. (2018). JMM17 Jurnal Ilmu Ekonomi \& Manajemen. Pengaruh Komitmen Organisasi, Quality of Work Life (QWL) Terhadap Organization Citizenship Behavior (OCB) Dan Kinerja Pegawai Pada Dinas Kependudukan Dan Pencatatan Sipil Kabupaten Bangkalan Madura Jawa Timur, Vol. 05 No. 01, hal. 24-36.

Suparjati, \& Priyono, B. S. (2018). Program Pasca Sarjana Universitas Stikubank Semarang. Mengkaji Variabel Organizational Citisenzhip Behavior Sebagai Mediasi Dalam Hubungan Variabel Kualitas Kehidupan Kerja Dan Kecerdasan Emosi Terhadap Organizational Citizenship Behavior Dan Dampaknya Terhadap Kinerja, 7383.

Tambe, S., \& Shanker, D. (2014). International Research Journal of Business and Management - IRJBM. A Study of Organizational Citizenship Behavior (OCB) and Its Dimensions: A Literature Review, Volume No - I.

Ticoalu, L. K. (2013). Jurnal EMBA. Organizational Citizenship Behavior (OCB) Dan Komitmen Organisasi Pengaruhnya Terhadap Kinerja Karyawan, Vol. 1, No. 4, 782-790.

Wenda, C. O. (2015). Pengaruh Quality Of Work Life Terhadap Komitmen Organisasional Karyawan Di CV Sinar Plasindo Agora. AGORA, Vol. 3, No. 2, 483-490. 